\title{
"No hay red como la ilusión": un acercamiento a la ética budista
}

\section{"There is no net like delusion": an approach to Buddhist ethics}

\author{
Elizabeth Corral \\ Universidad Veracruzana, México \\ corralelizabeth@gmail.com
}

Resumen: En estas páginas se busca comprender algunos términos del budismo (meditación, atención plena, preceptos, conocimiento intuitivo, naturalidad, despertar), que luego se examinan en pasajes de creación con personajes que parecen recrear la difícil práctica de "vivir en el presente" y aun los preceptos del Bodhisattva. Con ambos, intento entender mi práctica de zazen, que comenzó por recomendación terapéutica y en el camino se transformó en interés capital; ver cómo la fascinación por la lectura (aquí con ejemplos de Aira y Bellatin y la guía de Pitol) se transformó, con la práctica del budismo, en modelo de vida.

Palabras clave: ética, budismo, atención plena, literatura hispanoamericana, meditación.

Abstract: This paper seeks to understand some terms of Buddhism (meditation, awareness, precepts, intuitive knowledge, awakening), then examined them in creation passages where characters seem to adopt the difficult practice of "living in the present", and even the Bodhisattva's precepts. With both, I try to understand my own zazen practice, which began with a therapeutic recommendation and became a capital in- 
terest along the way; to discern how the fascination of reading, here with examples from Aira and Bellatin guided by Pitol, was transformed through Buddism practice into a model of life.

Keywords: Ethics, Bhuddism, Awareness, Hispanic American Literature, Meditation.

Recibido: 20 de enero de $202 \mathrm{I}$

Aceptado: I 5 de marzo de 202 I https://dx.doi.org/IO.I 5 I74/rv.vi3i28.594

Para Lilia Durán

No hay fuego como el deseo; no hay atadura como el odio; no hay red como la ilusión; no hay río como la avidez.

Dhammapada, LA ENSENANZA DE BUDA

Tace tiempo que persigo a los personajes que me parecen bución. César Aira tiene El pequeño monje budista, pero aquí quiero referirme a La vida nueva, donde el protagonista César Aira, un escritor no frustrado aunque no se haya dedicado a su vocación inconfundible, escribe desde su nueva vida. Y también a Salón de belleza, de Mario Bellatin, cuyo protagonista, una versión peculiar de Elisabeth Kübler-Ross, ${ }^{1}$ me recuerda a un bodhisattva, "aquel

1 "Un monje ataviado con una túnica color naranja se acercó al estrado en actitud reverente y se ofreció a aclararme algunas cosas [...]. En primer lugar, me dijo que aunque yo creía que no sabía meditar, existen muchas formas de meditación. / —Cuando está sentada junto a enfermos y niños moribundos, 
que hace el voto de despertar a la verdad última junto a los demás” (Chadwick: 461). ${ }^{2}$ El hechizo de la literatura está más allá de las palabras y la analogía con el budismo responde a una búsqueda más allá de la literatura, aunque parta de ella.

En su despertar, Siddartha Gautama el Buda discernió las Cuatro Nobles Verdades que hablan del sufrimiento, sus causas, su carácter finito y el camino para transformarlo, conocido como el Noble Óctuple Sendero. ${ }^{3}$ Este

recoge con minuciosidad excepcional, todas las actitudes y ejercitamientos para seguir la Senda de la Liberación [...]. Como el mismo Buda se ejercitó incansablemente en la meditación, por su propia experiencia directa, pudo indicar los métodos más pragmáticos, prácticos y fiables de cultivo psicomental, que son válidos para cualquier persona, cualesquieran sean o no sean sus creencias,

concentrada en ellos durante horas, está en una de las formas superiores de meditación" (92).

${ }^{2}$ La obra de Bellatin ha sido estudiada desde el sufismo, doctrina que el autor practica, como en la ponencia aun inédita que Gerogina Mejía-Amador presentó en las XVII Jornadas Andinas de Literatura Latinoamericana (México, agosto de 2020): "La desescritura y el no-ser en Mario Bellatín".

3 "Cuál es la Noble Verdad del Sufrimiento? Nacer es sufrir, envejecer es sufrir, morir es sufrir; la pena, el lamento, el dolor, la aflicción, la tribulación son sufrimiento [...]. / ¿YY cuál es la Noble Verdad del origen del Sufrimiento? Es el apego [...]. / ¿Cuál es la Noble Verdad de la Cesación del Sufrimiento? El completo cesar y desvanecimiento del apego [...]. ¿Y cuál es la Noble Verdad del Camino que conduce a la Cesación del Sufrimiento? [...]. El Noble Sendero Óctuple [...], compuesto por la recta opinión, el recto modo de pensar, la recta palabra, la recta conducta, el recto sustentamiento, el recto esfuerzo, la recta atención y la recta concentración" ("Primera lección de Buda", Buda y su enseñanza: 36). 
escribe Ramiro Calle en una sólida síntesis de la práctica de la que solo cito una parte. Calle comienza subrayando la incomparable investigación que el Buda dedicó al sufrimiento: "No ha habido nadie que lo haya investigado tanto y tan profundamente" ("Prólogo" a Anguttara Nikaya: 13).

Buda fue un ser humano, hijo de otros seres humanos, y eso hace de su enseñanza algo a lo que todos podemos aspirar. ${ }^{4}$ Con la práctica de la meditación se busca una mente lo suficientemente flexible y abierta para "comprender las cosas tal como son". Cuando nuestro pensamiento es flexible se habla de atención plena, una atención sin juicios a todo lo que ocurre en el momento presente, señala el maestro Shunryo Suzuki, mostrando la naturalidad como algo indispensable: "Es muy difícil explicar la naturalidad. Pero si puedes sentarte a meditar y experimentar la realidad de la nada, no tendrás necesidad de explicaciones", dice, y da algunos ejemplos esclarecedores: "La verdadera práctica del zazen es sentarse como cuando tienes sed y bebes agua. Ahí eres natural. También es natural que te eches una siesta cuando tienes mucho sueño" (Mente zen, mente de principiante: 109).

Una religión como el budismo, que alcanza los niveles más profundos del estudio de sí mismo, enseña al mismo tiempo un modelo de comportamiento ético que encamina a la liberación del sufrimiento. La práctica se centra en atender y aprender de la totalidad de nuestra experiencia, siguiendo en lo posible las indicaciones del Óctuple Sendero, donde "lo recto" es lo sustantivo, es decir, el Camino del Medio, "que se aparta de los extremos y pone

4 "Rigurosamente hablando, no hay necesidad de enseñar al alumno, porque el alumno es Buda mismo, aunque no sea consciente de ello. Y aunque sea consciente de su verdadera naturaleza, si permanece apegado a esa conciencia, está equivocado. Cuando no es consciente de ello, lo tiene todo, pero cuando toma conciencia de ello, piensa que aquello de lo que es consciente es él mismo, lo cual es un gran error" (Shunryu Suzuki: 70). 
especial énfasis en la observancia de la Triple Disciplina: la ética, la [...] meditación y [...] la visión lúcida o sabiduría" (Calle, Buda y su enseñanza: 15).

Madurar hacia la infancia: ese es el título que encontré un día en la mesa de Sergio Pitol, gran maestro de las lecciones indirectas. Lo mencioné en el libro que dediqué a su obra (La escritura insumisa: 8) y lo recuerdo ahora porque es de esos hallazgos que señalan una dirección. Me gusta la idea de volver a las maneras de la infancia, la "mente de principiante" o "mente del asombro" por antonomasia, con curiosidad por todo, sin los compromisos y exigencias extremas de la edad adulta, pero con la ventaja que dan una independencia y madurez entonces imposibles. Tengo la idea de que los niños muy pequeńos practican la atención plena sin saberlo, y que con los años, mientras sigue la infancia, quedan rastros de ella en medio del sufrimiento que supone el marco social y conceptual, fundado en la mente dual que el budismo seńala como una de las causas del sufrimiento.

\section{II}

Las enseńanzas planteadas por el budismo no son de orden meramente intelectual sino intuitivo, porque no basta con comprender las ideas sino que hay que colocarse en la misma perspectiva desde las que han sido concebidas. Y esta perspectiva, como escribe Félix E. Prieto, "es la de la naturaleza de Buda y su modo de ser es en todo momento el de la no-dualidad. Una no-dualidad entre sujeto y objeto, entre autor y lector, entre intérprete e interpretación" (12). Una no-dualidad que se extiende a todas las enseńanzas del Buda, que están más allá de los conceptos, de ahí que los textos se sustenten en la paradoja: "La forma es precisamente vacío y el vacío es precisamente forma [...]. No hay ignorancia, ni extinción de la ignorancia; no hay vejez ni muerte, ni extinción de la vejez 
o la muerte; no hay sufrimiento, ni causa, ni cesación, ni camino. No hay sabiduría ni tampoco logro" (7), leemos en El Sutra del Corazón de la Gran Sabiduría. ${ }^{5}$ Y líneas más adelante encontramos, me parece, una clave de la práctica: "Sin nada que lograr, los bodhisattvas [...] no tienen obstáculos en sus mentes; sin obstáculos no existen los miedos".

"Sin nada que lograr": una posición que difiere por completo de nuestra concepción inmersa en las metas y el éxito y por lo tanto en procesos mentales en los que el pasado y el futuro son los ejes de acción, olvidando el presente, lo cual, bien pensado, no deja de ser una extravagancia. Eihei Dôgen (1200-1253), uno de los maestros más destacados del budismo japonés y fundador del Soto Zen, ${ }^{6}$ describe en un pasaje muy famoso la manera de dar el giro que hace aparecer nuestra propia naturaleza de Buda: "Estudiar el Camino de Buda es estudiarse a sí mismo. Estudiarse a sí mismo es olvidarse de sí mismo. Olvidarse de sí mismo es ser actualizado por la multitud de cosas. Cuando la multitud de cosas se actualiza por sí misma, tu cuerpo y tu mente, así como el cuerpo y la mente de todos, desaparecen” (“Gengo Koan”, mD: 20). Poco antes había señalado cómo los budas, plenamente interconectados (el maestro Thich Nhat Hanh habla de "interser"), iluminan la ilusión que fabrica el ego: "Cuando los budas son verdaderamente budas, ellos no forzosamente reconocen que son budas" (MD: 20). Es más, cuando piensan que lo son, dejan de serlo. Buda inicia su última lección con estas palabras: "Pensad que lleváis dentro de vosotros la luz, depende de vosotros mismos y no de los otros" (Bukkyo Dendo Kyokai: 19). A fin de cuentas, "despertar" también es un concepto.

${ }^{5}$ Tomo las citas de los textos budistas del "Cuaderno de Cantos" de Montańa Despierta (en adelante $\mathrm{MD}$ ), mi lugar de práctica, y en la bibliografía incluyo referencias a ediciones públicas.

${ }^{6}$ Sobre el maestro Dôgen, véase en este dossier el trabajo de Tania Favela Bustillo. 
Entonces aprendi que era muy útil aprender a ser consciente de las condiciones sin juzgarlas.

Ajahn Sumedho

"El Gran Camino es fácil de seguir, pero la humanidad prefiere los senderos", leemos en el Tao Te Chin (73). Es la idea que subyace a las reflexiones de estas páginas, la paradójica facilidad contenida en la difícil práctica de vivir en el presente. Y claro que los senderos, como yo los entiendo, son atractivos, significan el aprendizaje de la vida a través de las historias que construimos para darle inteligibilidad a nuestro mundo, a nuestra realidad, y fuente eterna que alimenta a la aventura, la literatura, las artes en general y aun cualquier actividad humana. Pero son, también, materia del samsara.

Ajahn Pasano, en su prólogo a La Isla, apunta: "La naturaleza de lo que es considerado no dual empezó a cambiar para mí. Enseñanzas básicas comenzaron a tomar otro sentido. La enseñanza sobre el no yo, que es absolutamente fundamental, es un ejemplo. No se trata de una enseñanza oscura de los suttas: si hay algún indicio del yo, hay una posición que se toma y el reino completo del samsara se despliega" (19). La inteligibilidad de esto se afianza, me parece, en tres pilares fundamentales del budismo: la impermanencia, la interconexión y las leyes del karma, que aquí podemos entender en función de nuestras propias acciones y las consecuencias que producen. Parte de la práctica consiste en un autoobservarse continuo para ver los patrones de pensamiento, discurso, percepciones, emociones, reacciones que hemos aprendido o construido y con los que respondemos sin darnos cuenta, y buscar el mayor número 
de acciones que los maestros definen como "hábiles", es decir, las que provocan menos dolor. Se trata de conocerse adoptando cierta distancia, sin juicios ni penitencias, de la manera en que hablan los escritores sobre su tarea: escribir es convertirse en otro. El maestro Dôgen lo explica en "Recomendando el zazen a todas las personas": "Toma el paso hacia atrás y enciende la luz que ilumina hacia adentro", entonces "tu mente-cuerpo se caerá por su propio peso y aparecerá tu rostro original" (MD: 16). Y más adelante agrega: "La práctica-realización no puede profanarse, y no es especial. Es un asunto para todos los días" (MD: 18). ${ }^{7}$

La iluminación de Buda, dice Ajahn Pasano, exhibe "una manera de ver los fenómenos que nos alejan de la narrativa que creamos fácilmente, mostrando que la experiencia es sólo esas condiciones mentales y físicas funcionando juntas dentro de un cierto modelo -sea para la liberación o para el enredo-" (19; esto lo enseña la metaficción). Y Ajahn Amaro, en el segundo prólogo a $L a$ Isla, reconoce que aunque se señala el despertar como el objetivo predominante de la práctica, el énfasis del Buda está puesto en el camino, dado que "la verdadera naturaleza de la realidad última es necesariamente inexpresable por medio del lenguaje o de un concepto" (21). Sin embargo, añade, está al alcance de todos: "Tienen que confiar en esta simple habilidad que todos tenemos de estar totalmente presentes y totalmente despiertos, y comenzar a reconocer el aferrarse y las ideas que hemos establecido acerca de nosotros, acerca del mundo que nos rodea, acerca de nuestros pensamientos, de nuestras percepciones y sensaciones" (31).

Como yo la entiendo, la práctica consiste en irse desprendiendo de prejuicios y emociones que nos aíslan y observar en cambio el

7 "El trabajo de jardinería ha sido para mí una meditación silenciosa, un demorarme en el silencio. Ese trabajo hacía que el tiempo se detuviera y se volviera fragante" (Han: 11). Agradezco a María Deza por enseńarme este libro. 
funcionamiento de un enorme mecanismo dentro del que somos una pieza que cobra otra significación. En vez de la artificiosidad del ego de la que hablan los maestros, sugiere "la experiencia directa, desnuda, de la mente más allá o más acá de los conceptos, la mente del asombro, clara, fresca y fluida [...]. Es la Mente Grande en contraposición a la mente pequeña [...] No es una mente predescriminativa lo que buscamos, sino una mente post-discriminativa" (Sergio Stern, referencia oral). En "Cantos de la comida" encontramos estos versos: "Deseando el orden natural de la mente, / Deberíamos estar libres de la codicia, el odio y la ignorancia" (MD: 3). ${ }^{8}$ No conocemos ese "orden natural" pero puede buscarse en la práctica que empieza con la meditación en el zendo y alcanza luego todo lo demás. Como indica Thich Nhat Hanh, se puede Vivir el budismo -otro título guía- porque "cuando ves formas o escuchas sonidos, ocupando cuerpo y mente por completo, aprehendes las cosas directamente" (Dôgen, MD: 20). Se trata de estar en lo que se está, otra concepción en las antípodas de nuestro modo de vida, centrado en la multitarea. Para estar en el presente hay que abandonar toda idea o esperanza respecto al futuro y todo lamento o añoranza del pasado. "Concentración significa libertad", dice Shunryu Suzuki en Mente zen, mente de principiante. Y continúa:

Cada uno de nosotros debemos hacer nuestro verdadero camino, y cuando lo hagamos, expresará el camino universal. Este es el misterio. Cuando comprendes algo completamente, lo entiendes todo; cuando tratas de entenderlo todo, no entiendes nada. Lo mejor que puedes hacer es entenderte a ti mismo, y entonces lo entenderás todo [...]. Para ser independientes en este sentido

${ }^{8}$ Agradezco los comentarios de Sergio Stern a estas páginas; al igual que sus "Pláticas de Dharma" sobre algunos cantos budistas, han sido de enorme ayuda (Montaña Despierta, marzo 2020-mayo 2021). 
verdadero, tenemos que olvidarnos de todo lo que tenemos en nuestra mente y descubrir momento a momento algo nuevo y diferente. Así es como vivimos en este mundo (112-113).

Lo sorprendente del budismo es que la complejidad extrema se toca con la mayor simplicidad o, mejor, naturalidad; de ahí el peligro de caer en trivializaciones. Pero cuando la mente se calla, la naturaleza de cada uno surge interconectada y eso transforma todo, porque en vez de sentirnos en un lugar aparte, viviendo la vida como detrás de las barreras, nos integramos a toda la vida, lo que bien pensado debería ser lo "normal”. ¿Por qué nos creemos separados? ¿Por qué no nos sentimos, automáticamente, como "una demostración de los principios de la realidad"?? Dice el maestro Thich Nhat Hanh: "La vida es demasiado preciosa como para desperdiciarla en ideas, conceptos, enfados y desesperaciones. Podemos despertar a la maravillosa realidad de la vida y empezar a vivir plena y verdaderamente todos y cada uno de los momentos que componen nuestra vida cotidiana" (Estás aqui: 94). Abandonar los conceptos, dice parafraseando a Buda, es como dejar la canoa que nos permitió cruzar y que a nadie se le ocurre andar cargando después.

\section{III}

Muchos textos budistas son crípticos, algo que puede verse en el sutra que cité o en el koan zen. Pero me parece que esto apunta sobre todo a una ética que ilumina hacia lo profundo, aunque sería una profanación de la realidad creer que podríamos apresarla o representarla cabalmente. "Sin olvidar nunca lo transitorio de la

${ }^{9}$ Es expresión de Ayya Dhammadipa durante el curso "Imágenes del Ser" (2018); estas páginas deben mucho a sus lecciones. 
vida, os será posible dejar la codicia y la ira, y alejar al mal”, dice la última lección de Buda (Bukkio Dendo Kyokai: 21), que se refleja en los tres preceptos puros: abstenerse de las acciones que aumenten el sufrimiento, promover las que aumenten la atención plena y vivir para y con todos los seres.

Un dicho común en el budismo, según el maestro Ch’an Shengyen, reza: "Tomar los preceptos para romperlos es el camino del bodhisattva. No tener votos que romper es un camino no budista" (citado por Phelan), ${ }^{10}$ en el que, me parece, a la vez que se subraya la dificultad de la práctica, se indica la ausencia de castigos y culpas. Los Cuatros Grandes Votos contienen la idea de inalcazabilidad, pero aun así los hacemos: "Los engaños son inagotables, nuestro voto es terminarlos", dice el segundo de ellos. El maestro Shunryu Suzuki, fundador del Centro Zen de San Francisco, en California, decía: "Los preceptos. Aunque es casi imposible observarlos, debemos tenerlos. Sin meta o preceptos no podemos ser buenos budistas..." (Chadwick: 101).

Salvo los preceptos universales, los demás varían entre distintos países y culturas y pueden llegar a ser 358 para la vida monástica, pero los tres preceptos puros a los que me referí antes contienen todos los matices de estas guías para mejorar la calidad de vida. Los Diez Preceptos de la Mente Clara coinciden con lo que dictan

${ }^{10}$ Para el budismo las acciones no son ni buenas ni malas (moral, económica, estratégica, emocionalmente...), sino hábiles o inhábiles y se trata de la propia observación para detectar patrones que las disparan. La ética budista, definida con claridad en los preceptos, resulta una guía muy práctica, como dice Ramiro Calle, una serie de señalamientos que han demostrado por milenios cómo disminuir el sufrimiento propio; apunta primero al practicante, a su bienestar, sabiendo que el efecto solidario surge sin tropiezos cuando se tiene, aunque sea mínimamente, la experiencia de la interconexión. El maestro Thich Nhat Hanh, en Vivir el budismo, engloba todo en cinco preceptos universales que aquí sintetizo: no matar, no robar, no criticar, no ser sexualmente irresponsable, no intoxicarse. Luego hizo una reelaboración en catorce preceptos. 
otras religiones, son valores que definen a la humanidad, fundamentos para una actuación que disminuya el sufrimiento propio y ajeno. La ética budista busca "el cultivo de una postura sabia y compasiva que nos permita realizar la verdad de la interdependencia” (Sergio Stern, referencia oral).

\section{IV}

Contemplado no parece digno de ser mirado Oyéndolo no parece digno de ser escuchado Sin embargo si bebemos de él Nunca encontraremos su fin.

En Salón de belleza, Bellatin cuenta la historia de un marginal que construye un salón de belleza, contrata a dos amigos con los que comparte todo -trabajo, ligues, una cama enorme-, y decora su propiedad con peceras que convierten en acuario el salón entero. Luego, por azar, transforma el negocio de belleza en refugio para enfermos terminales. La ausencia de una geografía determinada y la sensación de tiempo desdibujado se acentúan por la afición del protagonista a pasar horas contemplando a las carpas doradas. Las peceras constituyen el ambiente en que se siente a sus anchas y lo reproduce vivencialmente en los demás espacios que frecuenta: "Es curioso ver cómo los peces pueden influir en el ánimo de las personas", señala (14). El estilo de la escritura, construida con un lenguaje sencillo, desapasionado, preciso, apunta a lo esencial y transforma en símbolo algunos signos recurrentes. Pero la densidad narrativa proviene de la multiplicación, sugerida en la imagen de los espejos del salón de belleza, "ese extrańo infinito que producen los espejos puestos uno frente al otro" (22). Así vemos que el 
claro paralelismo entre la vida de los peces y la de los hombres es apenas el primero de los varios planos del relato.

"Siento una alegría un tanto triste al comprobar que, de cierta forma, en los últimos tiempos el orden se ha instalado por primera vez en mi vida" (45), dice al final. La tristeza que se desprende de la fuerte sensación de soledad del protagonista se transforma pronto en curiosidad por la manera original en que va construyendo su vida -su verdadera obra- a partir de una serie de reglas que establece a conciencia según lo que se le va presentando. Y sus maneras no coinciden con las de su sociedad, así que transforma el salón de belleza en Moridero de desahuciados que cuida a su manera, ajeno a las prescripciones médicas y espirituales establecidas: ni entubamientos ni madres de la caridad, dice. Construye en cambio una moral sólida, ${ }^{11}$ opuesta a la practicada socialmente, distinta al discurso ortodoxo. En las épocas de esplendor, el salón de belleza da esperanza a las mujeres viejas que van en busca de juventud; en las de decadencia, el Moridero recibe casi cadáveres para que, a diferencia de lo que prevé para él, no mueran solos. De ninguna manera lo hace como un sacerdocio, afirma; la transformación se dio por casualidad, con la llegada del primer huésped terminal con que inauguró el nuevo giro del salón de belleza. No opuso resistencia, se dedicó a vivir lo nuevo sin remilgos. Es un hombre que explica asuntos de trascendencia -la vida, la muerte, lo sagrado, la lucha- a través del comportamiento de los animales y construye su

11 "Los dos [amigos] murieron contagiados y en el momento de la agonía los traté con la misma rectitud que al resto" (31); "caí en una depresión profunda, que sin embargo no me hizo descuidar en ningún momento a mis huéspedes" (37); "Buscaba evitar que esas personas perecieran como perros en medio de la calle o abandonados en los hospitales del Estado. En el Moridero contaban con una cama, un plato de sopa y la compañía" (50); "Aquí nadie está cumpliendo ningún sacerdocio. La labor obedece a un sentido más humano, más práctico y real" (61). 
vida con lo que se va presentando, preguntándose sobre el sentido que eso pueda tener y obrando a su entender: "Desde entonces y por las tristes historias que me contaban [de las agresiones de una banda de homófobos], nació en mí la compasión de recoger a alguno que otro compañero herido que no tenía a dónde recurrir. Tal vez de esa manera se fue formando este triste Moridero" (15). A mí me parece que el personaje despliega rasgos de un bodhisattva, una muestra de cómo el verdadero dharma emerge de uno mismo.

\section{V}

Hoy fue un dia bendecido por la risa.

\section{Sergio Pitol}

Me atraen particularmente los personajes que llamaría "no neuróticos", los que responden ecuánimes a su realidad. Creo que esto empezó cuando leí La vida nueva de César Aira, un relato metaficcional en el que el personaje César Aira toma el título de Dante para contar, ya muy avanzada su vida, la relación que por décadas tuvo con su editor, los muchos años que esperó la publicación de su primera novela, y reflexiona sobre sus posibles motivaciones de entonces, sobre ciertos rasgos de su carácter. Su "vida nueva" no tuvo nada que ver con la vocación sino con las circunstancias:

No podía imaginarme otra vida para mí que la de escritor. Pero quizás, en ese momento, no le daba tanta importancia a la publicación de ese libro. Ahí, el desinterés y la postergación encontraban una excusa [...]. Las cosas, en el mundo, en la literatura, en mi cabeza, iban demasiado rápido como para demorarme en lo ya hecho. Es comprensible, porque para un joven de veinte años, 
informado, lector, laborioso, la evolución es constante y veloz, casi atropellada, a saltos (15).

Fue en cambio un mal estudiante de administración de empresas y luego un exitoso hombre de negocios, se casó, tuvo hijos que se volvieron adultos. Ahora rememora su juventud y la relación con Achával, el "editor y recordado amigo" con que comienza la novela (7), como si fuera su remitente. Varias veces menciona el "lazo" que existía entre ambos y cuenta sin resentimiento los embustes del editor, cada vez más imaginativos e inverosímiles, y que él no ve como embustes. Conocemos la trayectoria del mundo editorial argentino, sus atmósferas y modas, a través de las conversaciones que por décadas sostienen los dos personajes, y entendemos que el "lazo" con Achával ${ }^{12}$ surgió del entendimiento:

Y él sí, aun siendo un hombre de larga militancia izquierdista y gran compromiso político y social, supo apreciar el soplo fresco de irreverencia que representaba lo mío y que no era otra cosa, según él, que la libertad intrínseca de la literatura, antídoto necesario a la seriedad o solemne empaque, ya francamente estalinista, que estaban tomando las ciencias sociales. De modo que me proponía publicar el libro en su propia editorial personal, que escapaba raspando a la categoría de editorial fantasma (11).

12 "Estábamos increíblemente sintonizados; desde el primer momento se había establecido entre nosotros una telepatía que nos impedía ocultarnos nada uno al otro" (25). "Las grandes afinidades generales daban por resultado las pequeñas coincidencias puntualísimas, como decidir llamarse el mismo día a la misma hora. Con el agregado en nuestro caso de que estábamos unidos, mejor dicho 'triangulados', por mi novela' (49). 
En vez de resentimientos o tristezas, y como la protagonista de la película El olor de la papaya verde, ${ }^{13}$ el César Aira de esta novela señala al "desasimiento central" de su carácter como la causa de todo. En una interpretación muy atractiva, Laura Estrín propone: "en realidad lo que la obra de Aira subtiende es una teoría de la felicidad" ("Los nuevos padres"), que me recordó el conocido experimento de neurociencia en el que Mathieu Ricard, un monje de la tradición tibetana, fue designado como la persona más feliz del mundo. ${ }^{14}$ Estrín agrega: "Aira es un escritor que lo único que quiere es seguir escribiendo, y el lector lo único que quiere es seguir leyendo", una conjunción feliz para el perseguidor de historias, que en Aira encuentra lo más disparatado, como las esponjas vivientes de los cómics, al tiempo que "hace pensar": "Pero, lo sepa o no, uno siempre está buscando esas afinidades formales, esas simetrías, o mejor: esas asimetrías, que deberían terminar poniendo en su lugar el caos e impulsos, intenciones, deseos, iniciativas de que

${ }^{13}$ Es un personaje instalado en el presente que parece representación del Metta Sutta: "Que se esfuerce por ser recta y sincera, sin orgullo / y que esté contenta con facilidad y jubilosa" (MD: 24), sentido que se refuerza por la analogía explícita con Buda en los dibujos del protagonista masculino (Cfr. "Le regard du Bouddha"). Con esto, me parece, el director vietnamita Tran Anh Hung da un cariz diferente a la anécdota. Si se entiende la aceptación budista como libertad al responder a las manifestaciones de la realidad, puede explicarse que sea rasgo del personaje menos encumbrado de las historias, como el de Bellatin, la joven de la película o Benigna, Nina, de Misericordia, de quien María Zambrano escribió: "Los personajes señeros, inconfundibles por su unidad, los que han actualizado su libertad, aun como Nina, sin darse cuenta, tan solo obedeciendo" (La España de Galdós: 53).

${ }^{14}$ Aquí, un par entre muchas ligas posibles:

https://www.ted.com/talks/matthieu_ricard_the_habits_of_ happiness?language $=\mathrm{es} \# \mathrm{t}-87851$

https://www.youtube.com/watch?v=BK7vb-hjHoY . "Desde la perspectiva budista, dice en esta entrevista, la idea es contribuir con algo a esta sociedad". 
está hecha la vida mental. En fin. No quiero explicarme, no es de caballeros" (Aira, Cómo me reí: 53).

Bajtín sostiene que el ridículo es nuestra segunda naturaleza, una idea que puede funcionar como detonador asociada a esta del maestro Suzuki: "Cuando puedes reírte de ti mismo, hay iluminación”, y hacer eco en la teoría de la felicidad en el subsuelo de la escritura de Aira que formula Estrín. "El milagro de la vida”, decía con asombro Sergio Pitol, otro escritor al que también le gustaba reír, es la "iluminación tras iluminación sin traza de iluminación" (Dôgen, apud Chadwick: 69).

\section{VI}

"El Gran Camino es fácil de seguir, pero la humanidad prefiere los senderos"... la increíble fuerza de la invención de los senderos y también la de esas palabras que se vuelven intocables: lo inefable, lo espiritual, lo sagrado, el despertar. El nirvana suena como algo imposible de alcanzar, historia y cultura influyen enormemente en el alcance y peso de los términos. Pero si pensamos el despertar como atención plena, la carga semántica se aminora. De ahí lo sugerente de propuestas como la de Gregory Bateson cuando marca un vínculo entre lo sagrado y la salud, ${ }^{15}$ o de Yannis Constantinidès y Damien Macdonald al escribir Nietzsche, el despierto. ${ }^{16} \mathrm{El}$ pri-

${ }^{15}$ En Una unidad sagrada. Pasos ulteriores hacia una ecología de la mente, sostiene: "Lo sagrado es la unión. / Lo sagrado es el empalme, el empalme total y no el producto de la división" (380), y lo asocia con la ecología de la mente: "La patología es algo relativamente fácil de analizar, pero la salud es algo mucho más complicado. Esta, por supuesto, es una de las razones por las cuales existe algo como lo sagrado, y la razón por la que sea tan difícil hablar de lo sagrado es porque lo sagrado es algo que está peculiarmente vinculado con lo sano" (338). 16 "Si bien no podría hablarse de fidelidad doctrinaria al budismo histórico, la filosofía nietzscheana puede de hecho interpretarse como una enseñanza del Despertar" (19), que para el filósofo alemán consiste en "reconquistar la es- 
mero apela a la unión y los segundos a la espontaneidad, entendida como la naturalidad en la cosmovisión de Shunryu Suzuki. En su biografía sobre este maestro zen, Chadwick escribe:

Empezaba a tener un atisbo de que el camino consistía en tener "una completa experiencia con pleno sentimiento en cada instante", no en utilizar cada instante para pensar sobre el pasado o el futuro [...]. Su punto de vista incluía la unidad, pero también lo opuesto: que cada instante, cada cosa, es distinta y debe ser considerada atentamente, no con vagas ideas de sentido universal (106).

Y entonces, como indicó el maestro Dôgen, se aprehenden las cosas directamente, porque "ves formas o escuchas sonidos, ocupando cuerpo y mente por completo" (Dôgen, MD: 20), como hacen los protagonistas de Aira y Bellatin, y los autores mismos en relación con su escritura y obra.

pontaneidad perdida [...]. La elección de este camino intuitivo conlleva [...] el rechazo del intelectualismo y de la abstracción esclerosante, y explica el acento puesto sobre la necesidad de educar y de espiritualizar el cuerpo. Por último, la voluntad de Nietzsche de oponer la eternización de esta vida a los sueños quiméricos de vida eterna, evoca irresistiblemente la idea de que el nirvana se revela ya en el samsara si uno cambia de actitud respecto a él. / La semejanza no se detiene en el contenido, sino que se extiende a la forma. Se encuentra así en Nietzsche el equivalente del koan zen, ese enigma sin solución destinado a mantener el espiritu despierto" (21). Agradezco a Enrique Flores el haberme enseñado este libro. 


\section{Bibliografía}

Aira, César, 2005, Cómo me reí, Beatriz Viterbo, Argentina. , 2007, La vida nueva, Mansalva, Buenos Aires.

Bateson, Gregory, 2006, Una unidad sagrada. Pasos ulteriores hacia una ecología de la mente, Rodney E. Donaldson (ed.), Alcira Bixio (trad.), Gedisa, Barcelona.

Bellatin, Mario, 1994, Salón de belleza, Tusquets, México.

Buda y su enseñanza, 2007, Ramiro Calle (intro.), Almudena Haurie, Simón Mundy y Ramiro Calle (trad.), EDAF, Madrid.

Bukkyo Dendo Kyokai, 2009, La enseñanza de Buda, $74^{a}$ ed., Tokyo. Calle, Ramiro, 1999, "Prólogo a la edición en castellano", Anguttara Nikaya. Discursos del Buda, Nyanaponika Thera (versión), Almudena Haurie Mena (trad.), EDAF, España.

Chadwick, David, 2001, Vida y enseñanzas zen de Shunryu Suzuki. Pepino Torcido, Fernando Pardo (trad.), La Liebre de Marzo, Barcelona.

Constantinidès, Yannis y Damien MacDonald, 2019, Nietzsche, el despierto, Pablo Ires (trad.), Editorial Cactus, Buenos Aires.

Corral, Elizabeth, 2013, La escritura insumisa. Correspondencias en la obra de Sergio Pitol, El Colegio de San Luis, México.

Dhammapada. La enseñanza de Buda, 1994, Narada Thera (versión), Ramiro Calle (trad.), EDAF, Madrid.

Dôgen, Eihei, 2004, "Recommending Zazen to All People", Beyond Thinking. A Guide to Zen Meditation. Kazuaki Tanahashi (ed.), Shambhala Publications, Boston, pp. 3-6.

, S/a, "Genjo Koan", San Francisco Zen Center. Disponible en: https://sanfranciscozencenter.blob.core.windows.net/ assets/24_Genjo_Koan.pdf (Consultado: 23/X/2020). 
, S/a, "Genjo Koan. Actualizando el Punto Fundamental” y "Recomendando el Zazen a Todas las Personas", en Cantos Zen, Montaña Despierta. Espacio para la práctica de la meditación inspirada en el Zen, Xalapa, Veracruz, México.

, 1994, "The Heart Sutra of Maha-prajna-paramita", Shobogenzo, Book 1, Windbell Publications, Londres.

Estrín, Laura, 2010, "Los nuevos padres", Desde el Sur, cap. 12, unNoba / AURa! Disponible en: https://www.youtube.com/ watch?v=vapLub64prg. (Consultado: 30/X/2020).

Han, Byung-Chul, Loa a la tierra. Un viaje al jardin, Isabella Gressee (ilustraciones), Alberto Cirla (trad.), Herder, 2019, 180.

Hanh, Thich Nhat et al, 2006, Vivir el budismo. O la práctica de la atención plena, Alfonso Colodrón (trad.), Kairós, Barcelona.

Hanh, Thich Nhat, 2011, Estás aqui. Descubriendo la magia del momento presente, David González Raga (trad.), Kairós, México.

Kübler-Ross, Elisabeth, 2010, La rueda de la vida, Amelia Brito (trad.), Ediciones B, Barcelona.

Lao-Tsé, 1976, Tao Te King, José M. Tola (versión y prefacio), Barral Editores, Barcelona.

"Le regard du Bouddha: L'odeur de la papaye verte de Tran Anh Hung". Ex libris (6 oct. 2010). Disponible en: https://ex-libris. over-blog.com/article-le-regard-du-bouddha-l-odeur-de-lapapaye-verte-de-tran-anh-hung-58382688.html (Consultado: $1 / \mathrm{VI} / 2020)$

"Matthieu Ricard sobre los hábitos de la felicidad", 2004, TED. Disponible en: https://www.ted.com/talks/matthieu_ricard_ the_habits_of_happiness?language $=$ es\#t-87851 (Consultado: 30/X/2020).

Pasanno, Ajahn y Ajahn Amaro (ed. y comentarios), 2018, La Isla. Una antología de las enseñanzas del Buda sobre Nibbana, Miguel 
Ángel Romero y Ricardo Szwarcer (trad.), Amaravati Publications, México.

Phelan, Josho Pat, 2002, “Tomando los preceptos y cosiendo el rakusu”, Rocío Hernández Pozo (trad.), en Hernández Pozo, Sutras, textos y recitaciones tradicionales Zen: Una lectura psicológica, Asociación Mexicana de Comportamiento y Salud, México.

Prieto, Félix E. (ed. y trad), 1989, Dogen, La naturaleza de Buda (Shobogenzo), Ediciones Obelisco, Barcelona.

Ricard, Matthieu, 2017, "El hombre más feliz del mundo", entrevista a Matthieu Ricard por Eduardo Punset. Redes, TVE. Disponible en: https://www.youtube.com/watch?v=BK7vb-hjHoY (Consultado: 23/X/2020).

Stern, Sergio, 2012, "Pláticas sobre cantos budistas con base en el maestro Shohaku Okumura", en Living by Vow. A Practical Intriduction to Eight Essential Zen Chants and Texts, Wisdom Publications, Boston.

Suzuki, Shunryo, 1970, Mente zen, mente de principiante, Miguel Iribarren (trad.), Penguin Random House, Estados Unidos.

Zambrano, María, 1960, La España de Galdós, Taurus, Madrid. 